
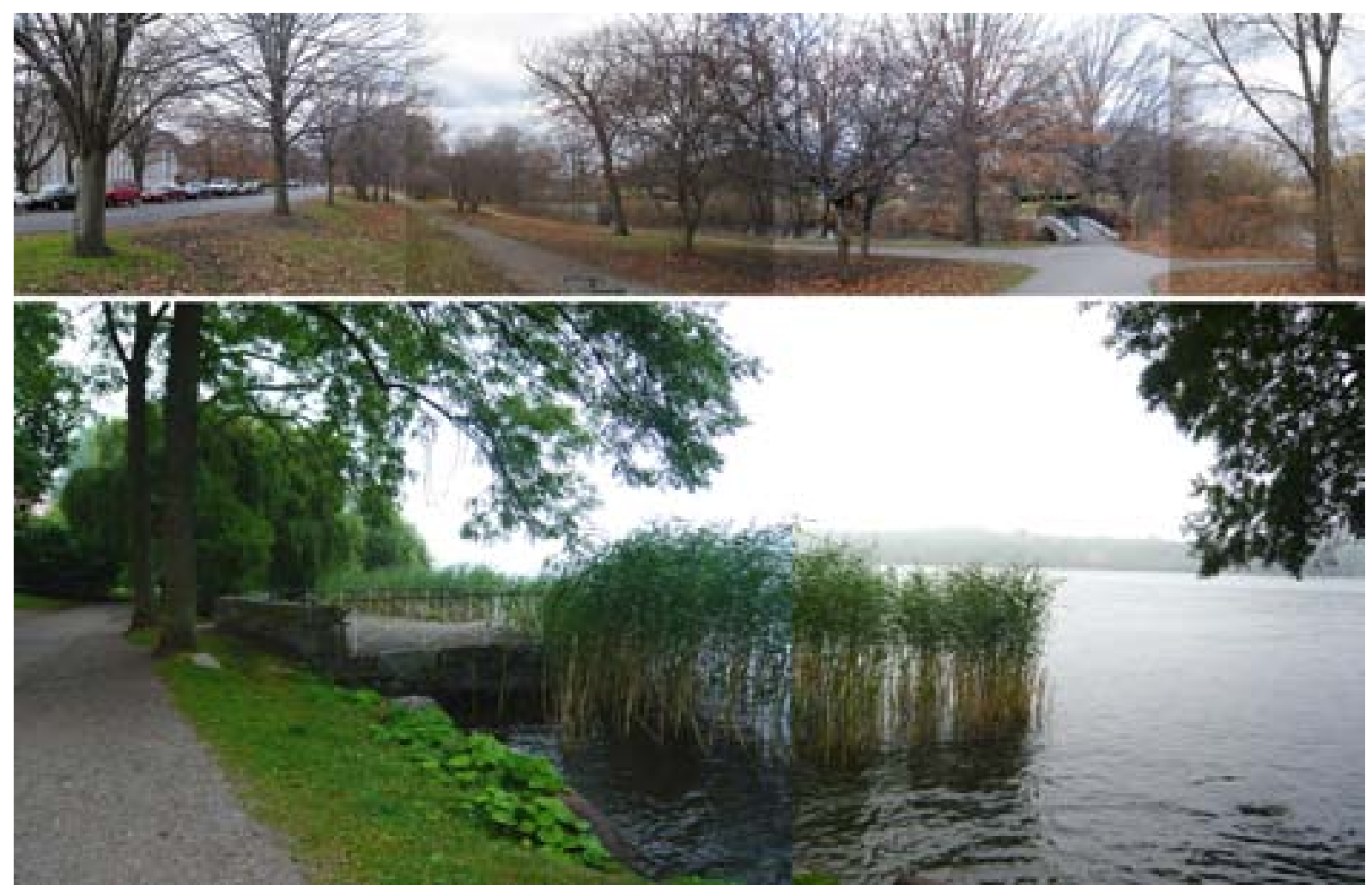


\section{Ecos de Olmsted en Europa. El sistema de parques y los origenes del urbanismo europeo contemporáneo Marina Jiménez}

Juan Luis de las Rivas

Con el diseño y la construcción del Emerald Necklace de Boston de Frederick Law Olmsted (1822-1903) tomaba forma una nueva herramienta urbanística directamente dirigida a adaptar el paisaje natural en el interior de la ciudad, concebida como sistema de parques, fusionando estructura urbana y diseño del paisaje. La idea sigue siendo esencial para pensar en una simbiosis entre ciudad y naturaleza. Sin ser exhaustivos, comprobamos como la idea se introduce en Europa de manera diversa y con logros dispares. A través de tres 'paisajistas' de generaciones que se suceden en el siglo $X X$, arraigados en contextos y lugares diferentes, queremos mostrar cómo el sistema de parques se consolida en Europa con perspectivas distintas aunque complementarias y que contribuyen a construir en la cultura urbano arquitectónica un camino de interacción entre ciudad y naturaleza, precedente directo de lo que hoy denominamos Green infrastructure.

\section{PALABRAS CLAVE}

F. L. Olmsted, sistema de parques, historia de la planificación urbana en Europa, diseño urbano

\section{KEYWORDS}

F. L. Olmsted, Park Systems, History of Urban Planning in Europe, Urban Design

El 'Collar Esmeralda' de Boston no es sólo un hito en la historia del diseño urbano y un precedente de instrumentos de planificación urbana sostenible como la infraestructura verde. Es la prueba de la larga duración de una idea hecha realidad en el instante que emerge el urbanismo moderno. No fue una aproximación teórica, fue una praxis, necesitada tanto de innovación en los principios del diseño urbano como de un conocimiento profundo de las dinámicas del paisaje por su capacidad para re-crear el genius locí. Allí Olmsted demostró el potencial de una comprensión sistémica, de relación e interacción entre partes, del paisaje natural en un emplazamiento urbano y la integración efectiva de los elementos del entorno local -agua, terreno, vegetación y todas sus dinámicas asociadas- con el desarrollo de la ciudad. Con el bagaje del paisajismo inglés, tanto de la reinterpretación del countryside

\section{Marina Jiménez}

Doctora arquitecta (Universidad de Valladolid) y Máster en Paisajismo

(Universidad de Valencia). Acreditada a contratada doctora. Profesora de Urbanismo en la Escuela de Arquitectura de Valladolid. Ha sido también docente en las escuelas de arquitectura de Oporto (Lusíada) y A Coruña (UDG). Sus investigaciones se centran en las relaciones entre naturaleza y ciudad, desde el diseño arquitectónico a la configuración del paisaje. Miembro del Instituto Universitario de Urbanística de la UVa, ha participado en diversos proyectos $I+D+i$ y ha intervenido en foros y realizado estancias de investigación en centros especializados (entre otros Penn University, Filadelfia; La Sapienza, Roma; UPEC, París; FAUP Oporto; Universidad de la República Oriental del Uruguay, Montevideo). Orcid ID 0000-0001-6590-4236

\section{Juan Luis de las Rivas Sanz}

Doctor arquitecto (Universidad de Navarra). Profesor titular de Urbanismo y Ordenación del Territorio en la Escuela de Arquitectura de Valladolid. Acreditado a catedrático. Ha sido director del Instituto Universitario de Urbanística de la UVa, participando activamente en su consolidación, y dirige el IUU_Lab, que desarrolla trabajos de investigación e innovación en urbanismo y planificación espacial. Ha participado en más de 20 proyectos de investigación nacionales e internacionales. Profesor visitante de múltiples centros de investigación (entre otros University of Texas, Austin; Politécnico de Milán; Universidad lberoamericana de Puebla; Instituto Universitario de Caracas...). Orcid ID 0000-0002-1235-1292

Fig. 01

Vista de un fragmento del Emerald Necklace de Boston a la altura de Fenway / Muddy River. Noviembre 2003. Imagen inferior: Vista de un fragmento del Rålambshovsparken \& Norr Mälarstrand de Estocolmo (Norr Mälarstrand / lago Mälaren), julio 2010. 
del XVIII, como de la cultura de sus primeros parques públicos, y del urbanismo del 'paseo' francés, Olmsted introdujo en la ciudad una nueva perspectiva capaz de proporcionar soluciones a problemas urbanos de estructura y metabolismo. El sistema de parques tuvo una clara influencia en los interesados por los espacios libres de la ciudad en el urbanismo europeo, desde pioneros como Howard, Geddes y Henard a arquitectos innovadores del Movimiento Moderno como Van Eesteren o Le Corbusier. Pero al menos estos últimos con referencias menores, dejando tras de sí sólo pequeñas contribuciones a las cuestiones que este texto pretende ilustrar. Hay que buscar en figuras aparentemente secundarias en el desarrollo de la disciplina urbanística para encontrar una referencia explícita al sistema de parques, más allá del interés genérico por el paisaje o por la relevancia del 'verde' en el futuro urbano². La crítica ha recuperado en Norteamérica la figura de Olmsted, dotándola del lugar heroico que le corresponde ${ }^{3}$. Este legado no ha sido tan evocado desde Europa. Los matices de su pensamiento han tenido menos reconocimiento que su 'sistema de parques urbanos', el cual sí se descubre pronto en el continente. Olmsted se conoce indirectamente, a través de sus trabajos en las ciudades americanas, visitadas por muchos planificadores europeos, y por su influencia en el City Beautiful Movement. Este Movimiento introdujo el sistema de parques en el ADN del planeamiento americano. Pero es sabido que el éxito de una idea incluye el riesgo de su banalización. Tanto el intenso y exitoso trabajo de la oficina liderada por sus hijos como la decadencia del Movimiento condujeron a cierto olvido del pionero. En cualquier caso, aunque las investigaciones sobre la fuerza motriz para incorporar la naturaleza en la planificación urbana europea moderna han identificado referencias específicas al trabajo de Olmsted, el hilo conductor de esta fuerza converge mayoritariamente en la idea misma del sistema de parques, mientras que la figura de Olmsted permanece más o menos presente según los casos.

Aquí surge la oportunidad de este artículo, como una exploración de tres figuras que son capitales en el desarrollo del sistema urbano de parques en Europa. Todos son 'compañeros' entre sí y también con el primer arquitecto del paisaje americano, no tanto por relación directa sino por 'afinidad electiva'. Pertenecen a generaciones posteriores al creador del Central Park, en una secuencia que va desde el francés Jean Claude Nicolas Forestier, coetáneo de los hijos de Olmsted, al alemán Leberecht Migge y, finalmente, al sueco Holger Blom. Cada uno propuso el sistema urbano de parques por distintas vías, con sus lógicas y limitaciones históricas, aportando luz a la construcción y evolución de una idea que es a la vez una nueva herramienta de planificación urbana en la Europa contemporánea. No tratamos los parques, sino su concepción sistémica que surge de una visión estructural sobre la naturaleza en las ciudades. Las interferencias entre estas figuras y los hechos históricos son también, de alguna manera, un eco de los pensamientos y trabajo de Olmsted. A través de la ideología y las circunstancias de cada figura, la idea seminal, el sistema de parques, se consolida en la base de una nueva visión urbana. El trabajo relevante de estos tres urbanistas en ciudades como París, Frankfurt o Estocolmo, permite todavía disfrutar de la inteligencia y habilidad que fueron capaces de introducir en sus diseños, evidenciando cómo encajar la naturaleza dentro de las ciudades para crear redes de espacios públicos y observar las estructuras urbanas como paisajes singulares. Cada uno de ellos comparte estas cualidades con Olmsted (fig. 02). 


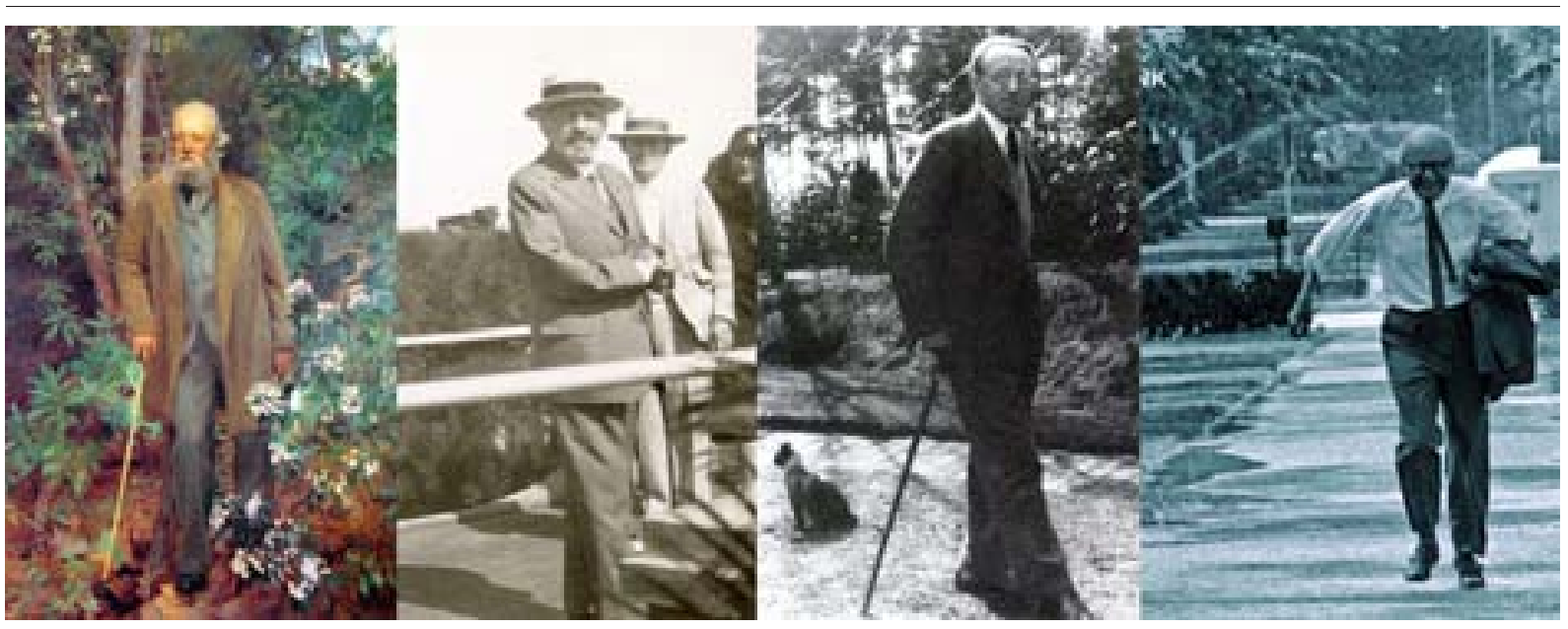

02

EN EL ORIGEN DEL SISTEMA DE PARQUES, F. L. OLMSTED
El legado de Olmsted pertenece a lo mejor de la cultura del urbanismo occidental. Su interés por comprender en profundidad los 'procesos naturales' dentro del paisaje urbano ha sido verdaderamente reconocido mucho más tarde. Conocedor de la naturaleza y de sus interacciones, con formación dispar pero integrada, interpreta con exactitud sus rasgos centrales dentro de la fábrica urbana. Autodidacta y viajero, incorporó lo que vio en Europa. Dos asuntos fueron hitos clave en su aprendizaje: el people's park británico y la promenade arbolada francesa. Olmsted aprende de los valores del Birkenhead Park diseñado por Paxton en Merseyside (Liverpool), o del Victoria Park de Londres, de la singular mezcla de belleza y reforma social recogida en los parques urbanos ingleses. En un París en transformación por los trabajos públicos, Olmsted descubre la nueva concepción de la movilidad urbana. Sus paseos a lo largo de la Avenue de l'Impératrice le revelaron la evolución de los boulevards y el carácter urbano del arboreto lineal francés. En el sistema de parques hay una combinación de estos dos factores, los servicios del parque del pueblo y la conectividad de los paseos arbolados.

Olmsted se forma indirectamente con los maestros del paisajismo urbano europeo, Paxton o Alphand, y traslada su aprendizaje a sus primeros trabajos. Esto se comprueba en el temprano Promenade que propone para San Francisco en 1865, de más de 6 kilómetros, deprimido para protegerse del viento, del tráfico y de las vistas a un entorno desolado, quizá su primer 'plan de espacios públicos' en secuencia y a pesar de que los administradores de la ciudad realmente le habían pedido otro Central Park. En 1866 en Nueva York intenta, con su socio de la primera mitad de su carrera, Calvert Vaux -inglés y arquitecto-, un plan de pretensiones intermunicipales, enlazando el Central Park de Manhattan con el entonces proyecto de Prospect Park en Brooklyn, con vías-parque nuevas o existentes, playas y riberas, desniveles, puentes e incluso transporte público. Comenzadas las obras de ese segundo gran parque neoyorquino, Olmsted propone a Buffalo su primera 'estructuraartefacto' natural completa: park, parade y front, cosidos por promenades, park-ways, y con places o circles intercalados ${ }^{4}$.
Fig. 02

Visionarios con los pies en el suelo: De izqda. a drcha. Olmsted en Biltmore: Óleo de J.S. Sargent, 1895. Forestier en Cuba: Plancha anónima, 1929. Fonds Théodore Leveau; Migge en Worspede: H. Saebens (últimos 1920s), aparece en HANEY, D. When Modern was Green, Routledge, Nueva York, 2010; Blom en Estocolmo (sin fecha), extracto de la portada de ÅSBRINK, B., Holger Blom..., 2012. 
Sin embargo éstos sólo son precedentes del que para nosotros es el 'verdadero' nacimiento del park sytem, que tiene lugar en Boston cuando hacia 1880 un Olmsted maduro tiene la oportunidad de transformar las riberas de un pequeño río, fangoso y sin forma aparente, en el conjunto coherente de espacios libres que hoy no es sólo un documento vivo sino que sigue siendo clave en la estructura de la ciudad. El Emerald Necklace es ejemplo de cómo los espacios libres pueden 'dar forma' a lo urbano y a la vez resolver aspectos básicos de su metabolismo cotidiano, como la recogida del agua de lluvia, la movilidad peatonal o el microclima urbano. Olmsted, consciente de la relevancia de este proyecto, escribía a su equipo en 1893: "Nada más se compara en importancia con el trabajo de Boston... Les haría declinar cualquier otro que se interponga en el camino de hacer lo mejor para Boston todo el tiempo"s. Cuando su discípulo directo Charles Eliot -director de su oficina entre 1893 y $1897-$ incorpora el territorio metropolitano a dicho sistema no hace sino ampliar una idea capaz de despertar otras y con potencial para movilizar la transferencia de conocimiento entre disciplinas. Todo esto ocurre con el tiempo y no sin dificultades, pero estamos en el nacimiento de una idea generalizable y con ecos concretos al otro lado del Atlántico.

Olmsted fue fiel al proyecto de atar la ciudad a su paisaje natural en cada uno de sus planes, que no siempre llegaron a realizarse pero que, cuando lo hicieron, alcanzaron una ejemplaridad notable. Ello sucede en Chicago, donde estuvo inmerso en proyectos continuados por sus hijos desde los 1870s hasta su retirada en 1893 (del South Park System a la World's Columbian Exposition), en Rochester (1888), en Louisville (1890).

Un poco más tarde, con el Plan de Chicago de 1909 (Burnham) a pesar de la lógica Beaux Art heredera del estilo 'Gran Ciudad' del París de Haussman y de la Viena Fin-dè-Siècle, podemos decir que la estructura verde penetra en la modernidad materializada como principio urbanístico, trascendiendo las ilusiones de la Ciudad Bella. Mucho antes, en 1870, Olmsted había pronunciado en Boston su conferencia "Public Parks and Enlargment of Cities". Cuando la ciudad americana apenas era un embrión de lo que sería, aunque ya se vislumbraba su crecimiento, él fue consciente de que el parque, y a través de éste la gestión sistémica del paisaje local en cada caso, debía adquirir un papel central en el proyecto urbano, y se dedicó a ello.

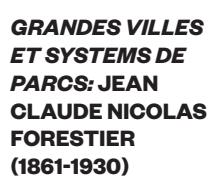

Con una amplia formación como paisajista, Forestier se definió a sí mismo como "un verdadero hombre de ciudades que ama el verdor y los jardines" ${ }^{\prime \prime}$ y se vinculó formalmente a la nueva disciplina del urbanismo, siendo uno de los fundadores de la Société Française de

Architectes et Urbanistes en 1911. Su especial sintonía hacia la visión olmstediana se demuestra en su querencia por vincular Grandes villes et systems de parcs, tesis que publicaba en 1908, donde recoge su empeño en que París despierte a la cuestión de los parques, y acaba pensándose a sí mismo como el 'sistemador' de sus espacios libres.

Contratado por Alphand a partir de 1887, aprende en el servicio de Promenades et Plantations de la ciudad parisina, en el que permanece durante 40 años. Su conciencia integradora aparece pronto, en el re-diseño de la Avenue Breteuil, donde la escala dada al espacio libre orienta la tipología viaria que organiza la extensión urbana. Algo que 


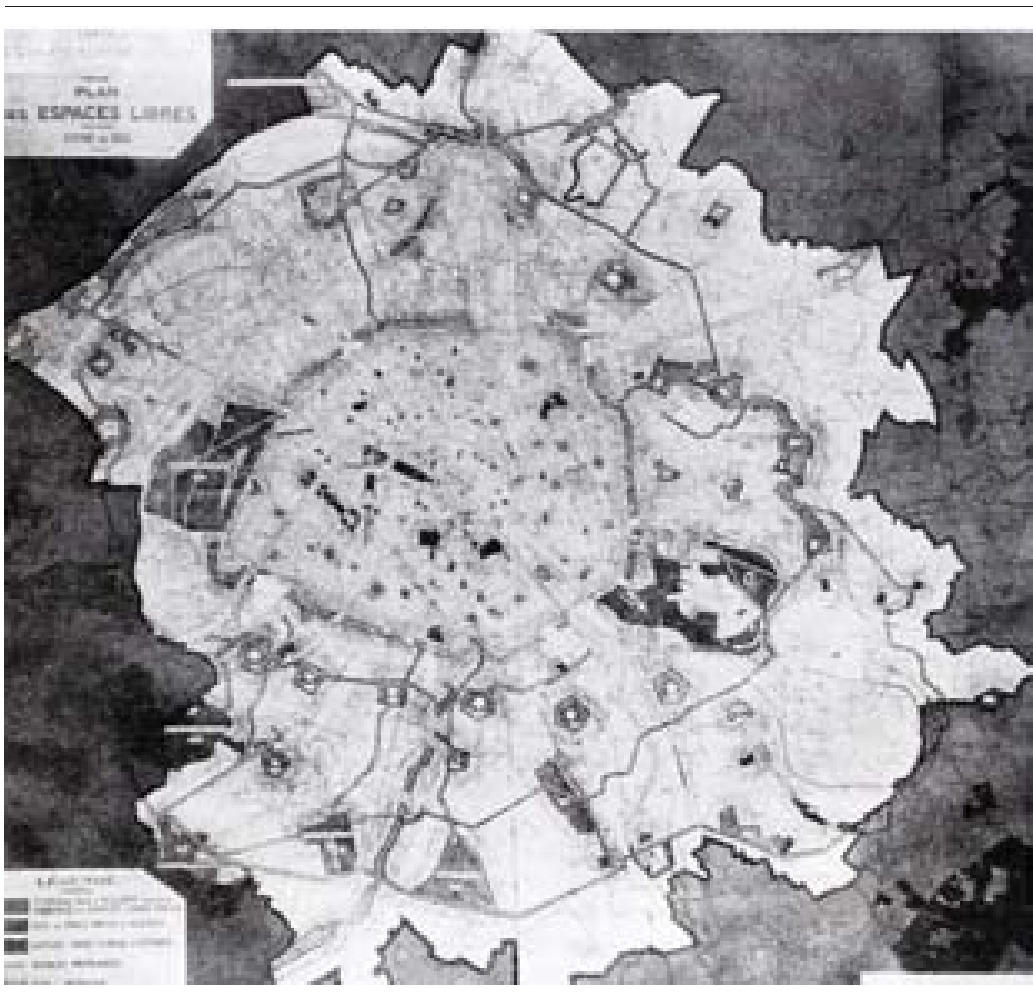

03

mantiene en propuestas sucesivas, en particular junto a los espacios que sustituyen las fortificaciones de Thiers, donde el "cinturón estira su halo blanco entre París intra-muros y las afueras". A la vez que despliega su actividad internacional como paisajista y urbanista no abandona la idea del sistema de parques, que se hace evidente en su Plan des Espaces Libres de 1924, abarcando todo el Departamento del Sena (fig. 03). Aquí su fe en la idea que inició Olmsted es profunda y madura:

"Es en la dimensión territorial donde se juega la distancia que separa a Forestier de Alphand... Para Forestier el jardín, el componente del proyecto urbano, se inserta en el proyecto territorial. Es el lugar de la mediación entre arquitectura y territorio. Forestier descubre e integra territorios. Es un topógrafo".

Antes Grandes villes et systems de parcs recoge con sencillez y originalidad su comprensión articulada de los espacios libres de la ciudad, de una forma tan metódica que sorprende. Están entonces en plena elaboración buena parte de los planes que el texto recoge, incluidos los americanos, por lo que su conocimiento del trabajo de Olmsted posiblemente sea indirecto e incompleto. Visitó Norteamérica más tarde, admirando algunos espacios que confirman su idea, como la Bronx River Parkway de Westchester (1907-1925): "nunca pensé que tuvierais nada tan hermoso como este bosque continuo", afirma.

Para abordar los orígenes de la idea de los sistemas de parques no hace referencia alguna a Olmsted. Cita Adelaida (Australia) y Letchworth, ambas a partir de la lectura de Garden Cities of To-Morrowde Howard. También aparecen Viena y Washington, y también Boston.

Fig. 03

Plan de Espacios Libres de Forestier para el Dpto. del Sena (1924). 
Figs. 04 y 05

De las Grandes Ciudades al Cuadernillo de plantas. Analogía o continuidad entre la portada de su primer texto (1908) y las ilustraciones de su "manual", (1920).
J. C. N. FORESTIER

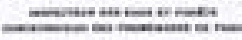

\section{GRANDES VILLES ET SYSTÈMES DE PARCS}

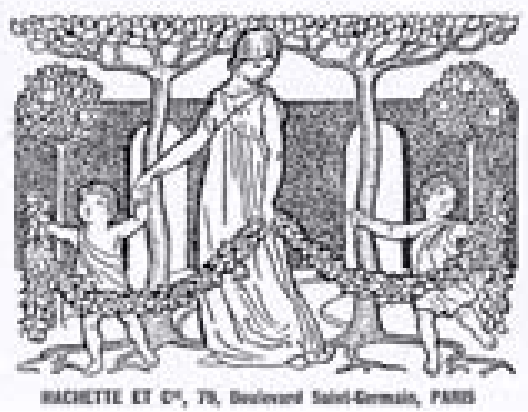

04

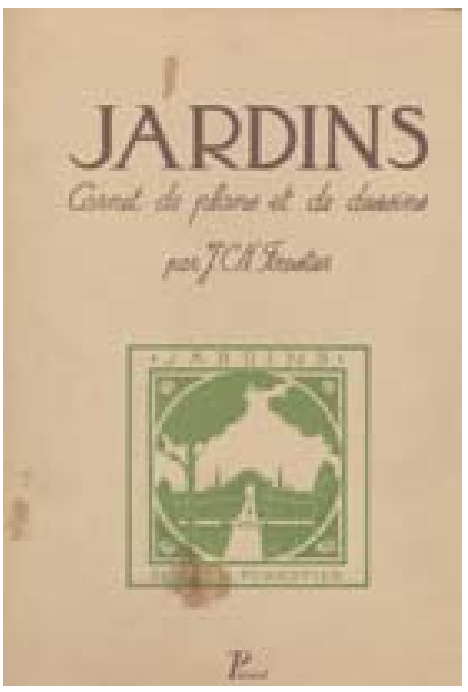

05

Los protagonistas son las ciudades y sus administradores de los que dice que comprendieron que el 'plano de la ciudad' era insuficiente si no estaba completado por un programa de conjunto que incluyera un plano especial de los espacios libres interiores y exteriores.

Forestier comienza su texto oponiendo un París dormido con uno en alerta, comparando su ciudad con otras ciudades occidentales y negando que ésta pueda pensarse a sí misma como algo 'terminado'. Sigue con su definición del sistema de parques a partir de sus componentes y distribución en la ciudad. Entre las piezas descritas asigna un valor particular a las Avenidas-Paseo (parkway, promenade, ring o anlage), que son garantes de la continuidad de una 'red estudiada', como ocurre en Boston, Chicago, Nueva York, Brooklyn y en los paseos de Austria, frente a meras 'operaciones aisladas'. Cuando trata los parques de algunas grandes ciudades, comienza y se extiende con Boston, atribuyendo el mérito a la Comisión nombrada en 1894 gracias a Eliot, que organiza, adquiere y gestiona el suelo y los recursos disponibles. También escribe sobre Nueva York, Chicago, Baltimore y Harrisburg (curiosamente en todas ellas trabajaron Olmsted o sus hijos). Concluye el texto invocando la necesidad de que París actúe en este terreno y reconozca que el aire, la luz, el verdor son imprescindibles si la ciudad no quiere su declive. Esta peculiar anticipación del mensaje de la Carta de Atenas presenta a un Forestier visionario y comprometido que, sin embargo, no encuentra apoyo suficiente en la ciudad que habita, el espacio donde aspira a desplegar sus ideas.

Efectivamente Forestier, muy conocido por sus jardines y parques, como los de Sevilla o Barcelona, sólo va a dar forma a su visión de conjunto, el sistema de parques, en laboratorios extranjeros: en la Península lbérica (década 1910), en Marruecos (1913); en Buenos Aires (1923) y en La Habana (1925-1929). Sus clientes le demandaban más París, es decir, proyectos urbanos fundados en grandes trazados tardo-barrocos y en el diseño de parques al estilo fin siglo, semejantes a los iniciados por Alphand. Sin embargo, su criterio adaptativo, de buen botánico, de respeto al clima local, le permitirá justificar su avance sobre el diseño beauxartiano de lo urbano. 
Su aproximación al sistema de parques ha quedado reflejada sobre todo en el papel, mientras que sus parques y jardines cuentan con la ventaja incontestable de su existencia real, como el Parque de María Luisa en Sevilla. Su concepción del sistema aparece con elocuencia en sus dos planes mejor armados, Buenos Aires y La Habana, donde se manifiesta de manera ejemplar su idea. Si el primero era más bien una reforma de la ciudad existente y el segundo un plan de crecimiento de la vieja ciudad colonial ${ }^{10}$, en ambos se reconoce una lectura paisajística que dota de sentido al sistema de parques como herramienta ordenadora. En las reformas propuestas para El Prado o el Malecón habaneros, o en el diseño y extensión de la Costanera bonaerense, se aprecia el paralelismo de su inserción del verde urbano con la secuencia bostoniana desde el Common y el Public Garden, pasando por la Commonwealth Avenue. Se enlazan parques que penetran en el corazón de los antiguos barrios y en los nuevos, con atención a la ciudad histórica y a la topografía, como en la loma del Príncipe y en las Quintas que incorpora en el sistema para La Habana. Forestier se apropia de cada lugar y dibuja sus perspectivas afirmando la necesidad de embellecimiento urbano pero también del plan regional. En ambas ciudades es fácil reconocer hoy elementos de la traza estructural planteada, contrapuesta definitivamente a los parámetros coloniales, sustituyendo la cuadrícula por el sistema vial jerarquizado de avenidas diagonales que vinculaban entre sí los nodos monumentales, buscando la inserción de grandes espacios verdes para formar un 'sistema' dentro de la ciudad. Así supera la marginación que genera la topografía y da valor a las particularidades naturales y a los accidentes paisajísticos del perfil urbano" (figs. 04 y 05).

PLANIFICACIÓN, REFORMA SOCIAL Y CULTURA JARDINERA: LEBERETCH MIGGE (1881-1935)
Investigaciones recientes han descubierto la figura 'ejemplar' del paisajista Migge en el periodo alemán de entre-guerras, insistiendo en cómo el paisaje no fue una preocupación irrelevante para los arquitectos de la vanguardia moderna. Así, su Manifiesto Verde, de 1919, es

"uno de los tratados más abiertamente políticos jamás escritos por un arquitecto paisajista"12. Migge se reconocía a sí mismo como un "Arquitecto para la horticultura', dando prioridad a los espacios de transición entre lo urbano y el campo, como ya hiciera Howard en su modelo de Ciudad Jardín, aunque sin negar la gran ciudad, en la medida en que "ya en 1913 había reconocido la existencia inevitable de la ciudad y definido a la metrópolis como 'la madre de los jardines"”.13.

Inmerso en su tiempo y en las contradicciones del mismo, desplegará su interés por el paisaje en los albores de una nueva era, racionalista y funcional, con influencias bastante directas de ideas de los herederos de Olmsted. La cultura urbanística alemana ya había introducido una lectura más o menos articulada del verde urbano, como se aprecia en Stübben, en Der Städtebau (1890), pero sobre todo en su escrito sobre La vegetación en la ciudad (1925), donde resume un amplio bagaje con referencias ya claras al 'park system' de Norteamérica ${ }^{14}$. Sin embargo quien introduce en Alemania la perspectiva norteamericana de los parques urbanos y metropolitanos es el urbanista y economista W. Hegemann, que hacia 1909 visita en Boston la firma de Olmsted y en ella conoce los trabajos del entonces recién fallecido Eliot. En 1910 
colabora en el montaje de la exposición Stadtebau en Berlín, incorporando sus conocimientos de la ciudad norteamericana, incluido el sistema metropolitano de parques de Eliot. Dos años más tarde en la exposición que prepara para Dusseldorf muestra materiales del plan de Burnham para Chicago y, junto a éstos, dibujos del primer parque diseñado para Hamburgo, el pequeño Fuhlsbütel Park (1909), de Migge, con el que ha entrado en contacto probablemente gracias a Muthesius. Hegemann es consciente de la influencia trasatlántica de la cultura del paisaje alemán, en particular de la figura de Pückler-Muskau, reconocida por el propio Eliot, pero también de la mutua influencia en ideas de ida y vuelta ${ }^{15}$.

Berlín y Frankfurt fueron, durante la República de Weimar, los laboratorios donde Migge junto a otros profesionales como Martin Wagner o Ernst May experimentaron con un funcionalismo amable y trataron de demostrar, mirando tanto a la ciudad-jardín inglesa como a la ciudad continua heredada, el papel mediador del verde urbano, ofreciendo al paisajista una visión sistémica creemos que asimilable en parte a las de Olmsted y Forestier.

Migge comienza muy joven su formación como jardinero. En 1910 viaja a Inglaterra para conocer de primera mano el movimiento Ciudad-Jardín y en 1920 se establece en Worpswede, colonia de artistas desde el XIX, donde convive con Bruno Taut entre otros, y crea una escuela para la enseñanza de jardinería a jóvenes, ampliada en 1924 con una oficina de dibujo, y desde 1926 con oficina también en Berlín. Con planteamientos reformistas, concebidos 'desde la tierra', se implica en las acciones de la vanguardia moderna, siendo desde 1912 miembro de la Werkbund. Pero, sobre todo, Migge es un experimentado paisajista que comienza muy pronto a diseñar parques, en Hamburgo y Leipzig, donde enraíza y se despliega una idea sistémica de los parques urbanos ${ }^{16}$ :

\footnotetext{
"A Migge le gustó el concepto de sistemas de parques interconectados, dándoles una variedad de funciones sociales y expresiones espaciales. Adoptó el modo americano de integrar prados y bosques como parte del paisaje cultural del parque, y como espacios que podrían ser utilizados para reuniones públicas".
}

Durante la $1^{\mathrm{a}}$ Guerra Mundial concibe una serie de estrategias que denomina "Planificación Verde" y que aplica por primera vez en Rüstringen, donde había conocido a M. Wagner en 1911. El primer paso, dice, es el "Archivo Verde", inventario de los espacios libres verdes existentes junto con otros elementos naturales y espacios de significado histórico relevante. A ello le sucede el análisis de las 'zonas de influencia' - préstamo de Wagner, como estándar urbanístico o ratio de área de parque para cada barrio a menos de media hora de paseo-, a partir de la distribución global de pequeños parques interiores, en conexión con los 'espacios abiertos' y con una red proyectada de promenades verdes. Estamos ante el primero de sus esquemas sistémicos.

Sólo más tarde, en 1922, Migge plantea por primera vez un cinturón verde completo en Kiel y entre 1924-1926 diseña en la ciudad de Celle para el arquitecto municipal Haesler, su primera Siedlung, Georgsgarten. Y son sus colaboraciones con Wagner, arquitecto municipal de Berlín a partir de 1925, y con May en Frankfurt, las que le permiten desarrollar de forma más integrada, en la planificación, su visión sistémica de los espacios abiertos. 


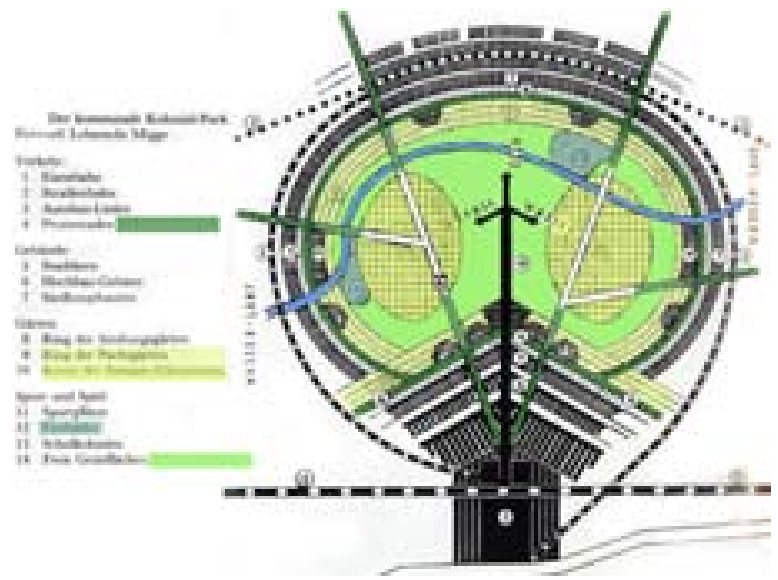

06

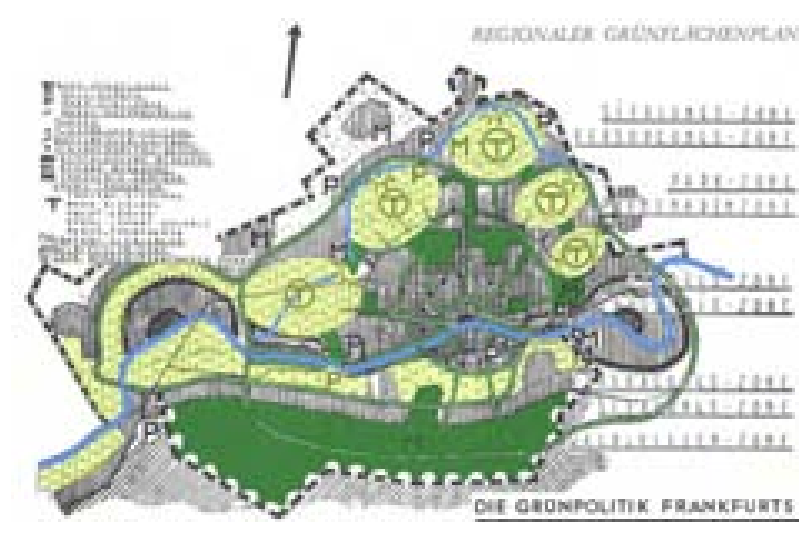

07
En Berlín, donde la gestión municipal existente ya había incorporado piezas naturales con cierta función ordenadora, Migge participa en las siedlungen Zehlendorf (desde 1924), Britz (desde 1925) y Siemensstadt (desde 1929). Britz, sólo realizado en parte, es posiblemente el diseño más sugerente de Migge por su articulada sincronización de agua, topografía y huertos, en un plan urbano donde la secuencia de verdes es protagonista. En contraposición, en Siemenstadt desaparecen las subdivisiones de jardines vecinales, se retrae el huerto y aparece el bosque con grandes espacios contiguos que mantienen el carácter de los primitivos prados. La colaboración de Migge con arquitectos de talento como Wagner y Taut le facilita materializar la articulación de un espacio libre que arropa y sustenta el diseño urbano y arquitectónico. En los tres casos citados se pueden apreciar variaciones en la concreción de dicho espacio, pero siempre con una concepción mucho más amplia que la del diseño de un parque o jardín concreto. En 1930 Hegemann incorpora en Das steinerne Berlin el esquema sistémico de Wagner (1929) que muestra este conjunto estructurado de espacios libres para el Gran Berlín.

Todo ello se hace más evidente en Frankfurt, ciudad de menor escala que permite a Migge desplegar un pensamiento práctico más abarcante. Lo realizado junto al río Nidda en la siedlung Römerstadt participa y es parte de la interpretación del conjunto urbano, tal y como se defiende en el Plan Regional de Espacios Libres que Migge plantea en 1928 para la ciudad. Allí el 'papel mediador' del espacio natural en el diseño urbano adquiere un valor que no se ha destacado lo suficiente. Con su 'parque municipal colonizador' su investigación teórico-práctica alcanza una forma más radical y coherente de desarrollo de un proyecto conjunto de áreas verdes urbanas. Se funda en la propuesta de un nuevo tipo de Volkspark, donde el engranaje verde y los espacios productivos (huertos populares) están al servicio de la interacción ciudad-campo ${ }^{17}$, tema éste de gran interés y actualidad. El sistema verde de Frankfurt encuentra en el trabajo de May y Migge un enganche con sus principios generadores, en una lógica de sistema urbano policéntrico con nuevos barrios satélites, el Trabaten Prinzip de May, donde los espacios libres - parque-colonizador-son el cemento que suelda las piezas urbanas ${ }^{18}$ (figs. 06 y 07 ).
Figs. 06 y 07

Esquemas de Migge para Frankfurt, Diagrama del parque comunal y Política del verde en Frankfurt o Plan Regional de Espacios Libres: el modelo y su ajuste a un caso real. 
ADMINISTRAR

EL SISTEMA

DE PARQUES

URBANOS:

HOLGER BLOM

(1906-1926)
El escritor sueco T. Danielsson escribía en 1965, "Cantan que 'Sólo Dios puede hacer un árbol', pero entonces ¿alguna vez has pensado en el jardinero urbano Holger Blom?" arquitecto que, durante tres décadas al frente del departamento de parques de Estocolmo -1938-1971-, no sólo promovió una política coherente y estratégica de parques urbanos, también desarrolló con éxito un sistema de parques capaz de penetrar en casi todos los espacios de la ciudad existente ${ }^{20}$. Imprescindible para comprender lo que algunos denominan el "estilo de Estocolmo", Blom fue el 'dinámico jardinero', recordado en su ciudad con respeto por su preocupación cívica y trabajo artístico ${ }^{21}$. Aunque sin noticia de referencias concretas a Olmsted en su trabajo -sí a Eliot-, no nos es difícil apuntar un vínculo virtual entre ambos.

Con una formación arquitectónica sólida y cierta experiencia urbanística tras pasar por la oficina de Le Corbusier en París, Blom comienza a dirigir el Departamento de Parques de Estocolmo con apenas 32 años, sucediendo en ello a Osvald Almqvist (1884-1950) que lo había puesto en marcha en apenas dos años y ya había iniciado un "cinturón verde" para el área metropolitana y pensado en la cohesión de las grandes zonas de parque de la ciudad, con sendas verdes de unión. Estocolmo era una ciudad de industrialización tardía, a partir de los años 30 , sometida a un rápido proceso de urbanización que se desarrolla sobre el fondo de un paisaje autóctono relativamente bien conservado. Se contaba con la ventaja de un gobierno urbano preocupado por dotar de infraestructuras y servicios a un territorio en trasformación, mientras que el respeto por la naturaleza se apoya en esa calidad original del paisaje holmiense, en la singularidad de su emplazamiento y en una cultura más que paisajística, horto-botánica, muy arraigada ${ }^{22}$.

La colaboración, a finales de los años 20 , de arquitectos de la talla de Almqvist, Asplund, Lewerentz y Markelius en los trabajos de la Exposición Universal de 1930, crea un clima particular en la ciudad y permite configurar al Este, junto al canal Djugard, un sector destinado a grandes parques y equipamientos culturales. Son nuevos espacios que recuerdan las actitudes esenciales del disfrute social y natural del paisaje -exertive or receptive- pensadas por Olmsted, y en los que se manifiesta una 'tercera vía' del proyecto de la vanguardia moderna, caracterizada por la armonía entre arquitectura y paisaje. En este contexto de convivencia Blom impulsa sus proyectos, animado no sólo por la sensibilidad hacia la naturaleza sino por un conocimiento preciso del paisaje local, en el que le asisten expertos como Erik Glemme (1905-1959), uno de los pocos arquitectos paisajistas de formación en su entorno, reclutado por Almqvist y que fue jefe de diseño del Departamento de Parques hasta 1956.

Los resultados van a dar forma a un modelo singular de integración del parque en lo urbano ${ }^{23}$. Clave en todo ello es la red verde que Blom concibe tanto 'infiltrándose' en la ciudad existente como penetrando en la ciudad-región. Hay en ello algo más que talento paisajístico, existe una visión estratégica del proyecto urbano que mira a largo plazo, y que sería imposible si Blom no hubiera dado importancia a los medios políticos y de información, con los que se relaciona con sencillez y elocuencia ${ }^{24}$, consciente como lo fuera Olmsted de la interacción entre naturaleza y democracia. "El parque alivia ['abre'] la ciudad: el parque debe ser un componente activo del desarrollo urbano, formando redes a través de la ciudad, y no solo un oasis verde aislado"25. 


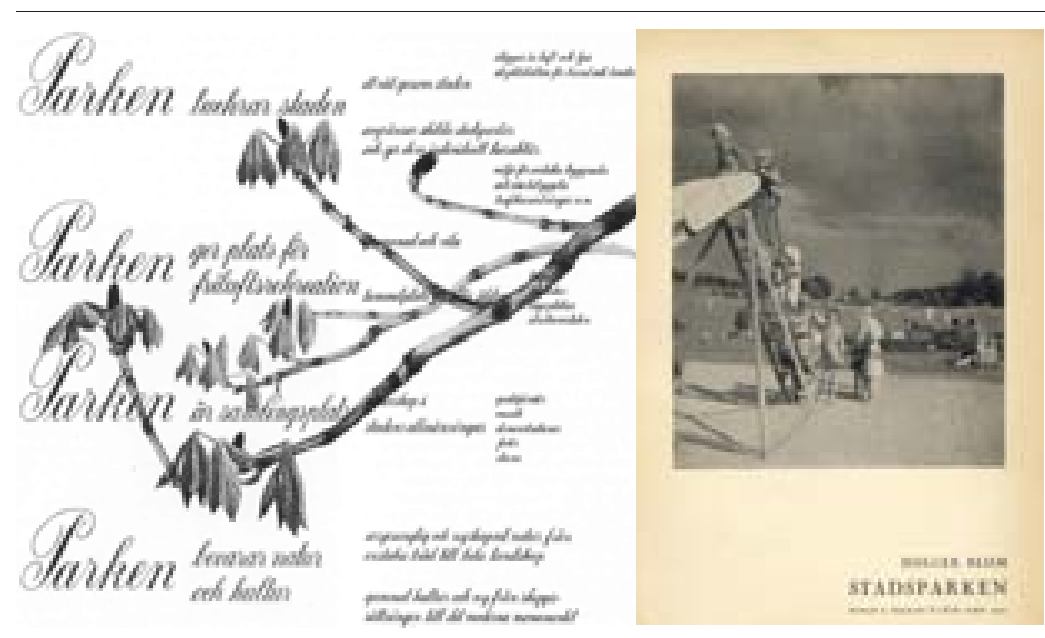

08

09

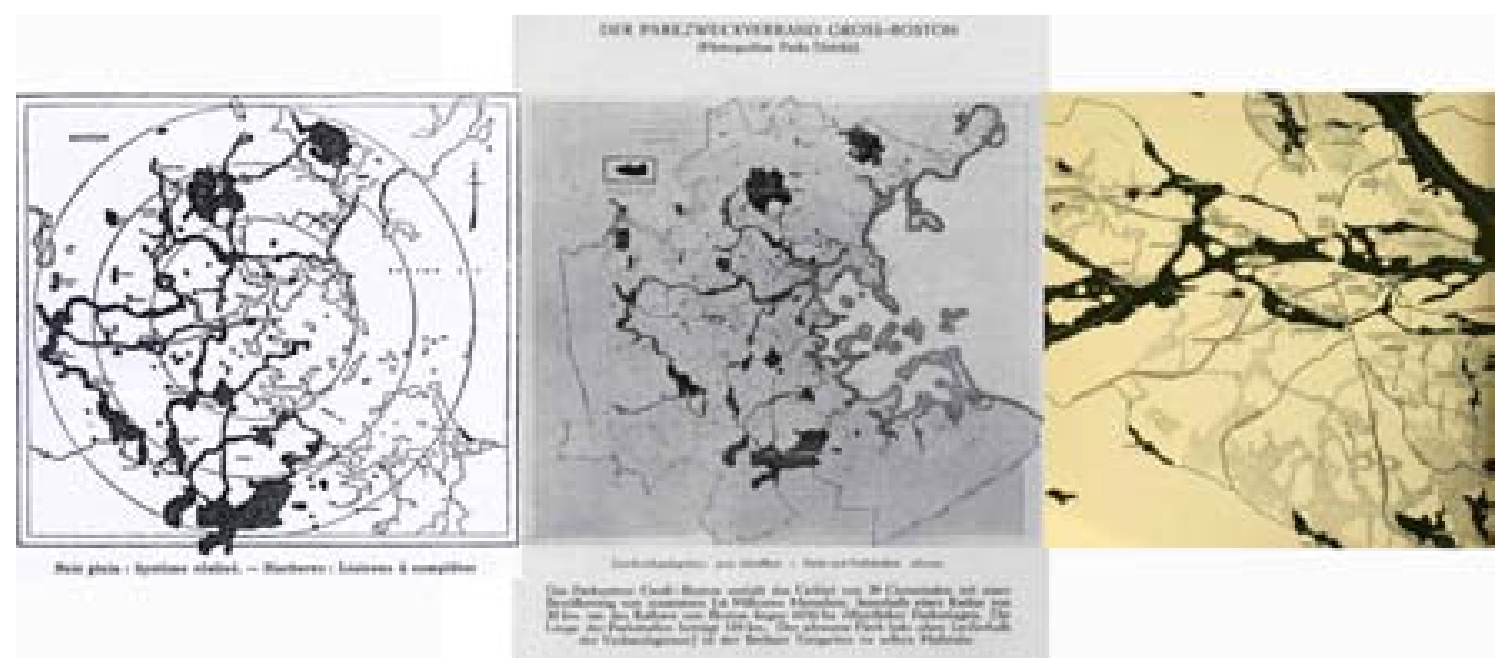

10

Así y bajo el lema "todos los jardines son naturales", la Escuela Holmiense se consolida recreando los rasgos del paisaje regional dentro de los parques urbanos -nuevos y existentes-y buscando un diálogo fructífero entre edificación y espacio abiertos (figs. 08 y 09).

Mención especial merece la cadena de parques de Rålambshovsparken \& Norr Mälarstrand, con 3,5 kms de desarrollo en la ribera del lago Mälaren, a la que se suman otras intervenciones relevantes al Norte, en Norrmalm. Desarrollado entre 1941 y 1943, aunque añadiéndose espacios hasta los 50s, la secuencia se materializa con la apropiación de los diferentes espacios y elementos naturales e incorporando piezas existentes en un ensamblaje único y a la vez diverso, con el agua como protagonista, conectando sin interrupción la ciudad interior con su perímetro ${ }^{26}$.

Este es un caso importante no sólo por su impacto en el campo del diseño paisajístico como se reconoce en los dibujos de Blom para su Programa de Parques de 1946, sino porque se propone desde una escala urbana más amplia. Su representación esquemática de la red de parques de Estocolmo (fig. 10) pertenece a la idea de la ciudad como paisaje total ${ }^{27}$, asociando lugares y parques urbanos acumulados a lo
Figs. 08 y 09

Programa de Parques de Blom; y libro de difusión publicado en 1940.

Fig. 10

De izquierda a derecha: El Park system urbano-metropolitano de Boston como lo ilustran Forestier (1906) y Hegemann (1911), ambos reinterpretando a Eliot, y el sistema para Estocolmo de Blom (1946). 
largo de siglos e incorporando otros con 'naturalidad', desde el Cementerio del bosque a museos al aire libre ${ }^{28}$. El diseño de este engranaje verde global ha adquirido en Estocolmo una relevancia casi tan clara como la del pionero Emerald Necklace y su ampliación en el Metropolitan Park System of Boston ${ }^{29}$.

Efectivamente, el trabajo de Blom también se relaciona con el de Sven Markelius, responsable de la Dirección de Planeamiento Urbano a partir de 1944 y que introduce en Estocolmo la dimensión metropolitan $\mathrm{a}^{30}$. Markelius plantea la complementariedad del centro urbano existente, convertido en centro direccional, con un sistema de nuevas comunidades o ciudades-satélite distribuidas como perlas a lo largo de las líneas de metro. Su 'negativo' es la naturaleza más o menos virgen que adquiere una función protectora activa, interfiriendo con el patrón heredado de desarrollo radial en cuñas verdes y evitando que sea sólo el transporte el que defina el modelo urbano regional ${ }^{31}$. El plan de Estocolmo, aprobado en 1952, dispone así de una estructura capaz de proporcionar espacios libres accesibles y ecológicamente beneficiosos, estructura que alcanza la escala cívica de las nuevas comunidades ${ }^{32}$.

Prácticamente desde entonces, reconociendo éxitos pero también fracasos (sobre todo en algunas ciudades-satélite), Estocolmo trabaja intensamente en el desarrollo de planes y documentos que describan las funciones y valores de la estructura verde en relación a la biodiversidad y también a las cualidades sociales. No se puede olvidar a Blom, porque para materializar la visión sistémica del paisaje no basta con el conocimiento y la ecología, también es necesario 'diseño'.

APRENDIENDO A PROYECTAR LA CIUDAD CON LA NATURALEZA. EPÍLOGO
Las tres imágenes de la figura anterior (fig. 10) muestran cómo el 'sistema metropolitano de parques' es una constante en la que la referencia a Eliot y Olmsted parece imprescindible. La trasmisión de una idea, la necesidad de apropiarse del paisaje local y de la escala regional

para acomodar lo urbano a su entorno natural, ha penetrado el urbanismo contemporáneo, aunque sin duda más en la teoría que en la práctica real. Hoy son incontables los casos de ciudades con sistemas de parques definidos como tales, pero las figuras complementarias de Forestier, Migge y Blom nos recuerdan que no se trata sólo de elaborar un plano. Las escalas urbana y regional se alimentan mutuamente, sólo así es posible un primer gran objetivo, la integración de la ciudad en su entorno natural. Y lo más difícil es hacer todo ello viable, es aquí donde la colaboración entre urbanismo y arquitectura -del paisaje-, con su diseño oportuno y su visión de futuro, se cumple en la correcta interpretación de los lugares y en el acertado conocimiento del arte de los jardines, no sólo flora y clima sino proyecto que trabaja con agua, relieve y arquitectura.

Cada uno de nuestros paisajistas es dos décadas más joven que el anterior y a cada uno le corresponde un perfil definido y diferente, a la vez cerca y lejos de la persona y del proyecto que Olmsted construye para sí mismo. Forestier viaja por el mundo, Migge trabaja sólo en un puñado de ciudades alemanas y Blom apenas sale de su ciudad, pero los tres comparten la visión abarcante que hace de los espacios abiertos un argumento imprescindible del diseño urbano. El paisaje articula y compone el 'sistema' donde lo urbano y la naturaleza que lo sustenta pueden establecer un diálogo positivo. Forestier propone un 
Fig. 11

Dibujos o fotografías de actuaciones de las cuatro figuras. De arriba a abajo: La Long Meadow en el Prospect Park de Brooklyn (Olmsted); Av. Universidad desde las terrazas de la Universidad, al fondo loma del Príncipe, La Habana, Frankfurt (Forestier, coloreado propio); Desde los baluartes de Römerstadt hacia el Valle del Nidda (Migge); Nör Mälarstrand hacia el Mälaren, Estocolmo (Blom-Glemme).
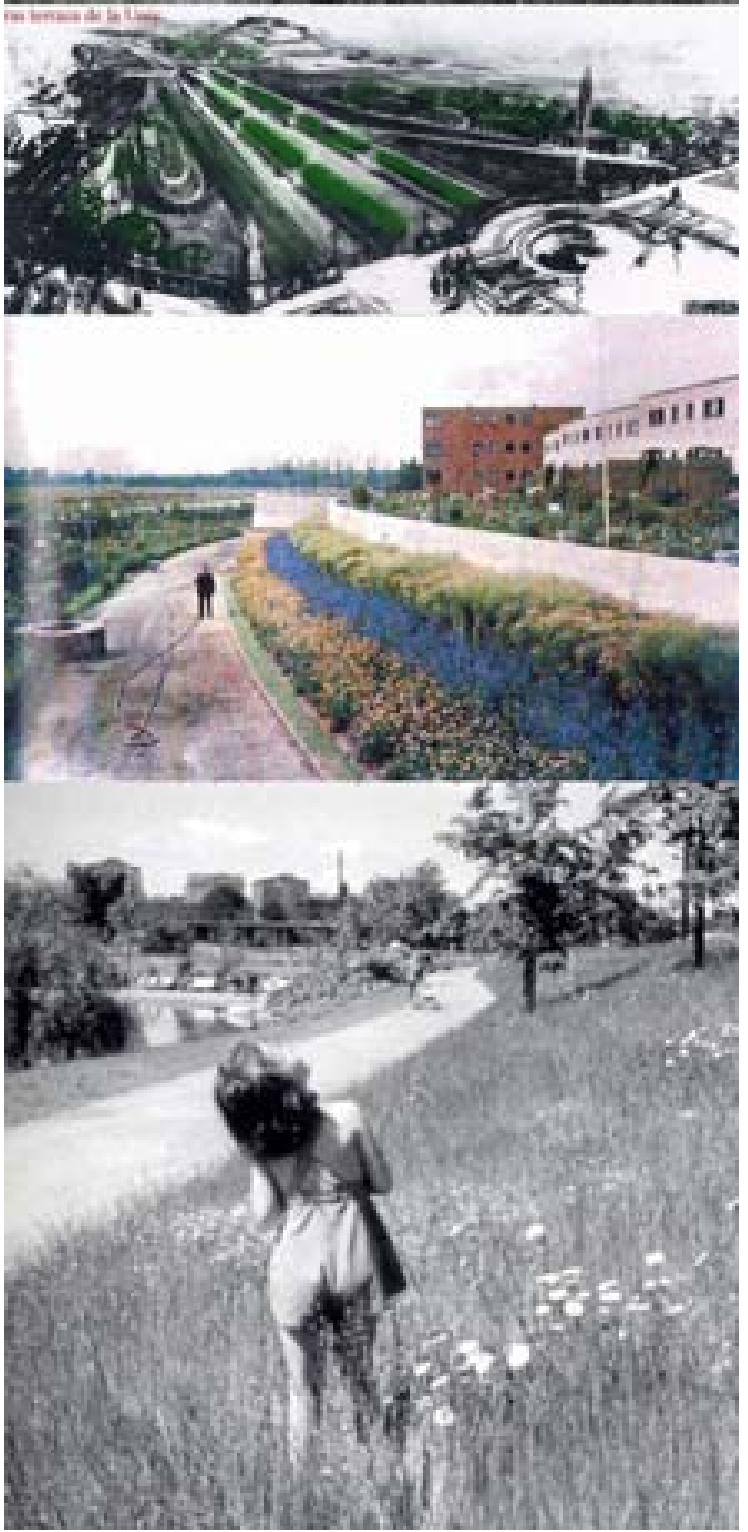
aparato técnico al servicio de lo urbano pero que se hace visible por su saber de artista del paisaje. Migge emprende una aventura reformista que ve en el huerto urbano oportunidades que hoy se comienzan a ver de nuevo. Blom ofrece en el servicio público una dedicación constante a la construcción y gestión de un paisaje concreto, dando cuenta de la eficacia de un talento que se aplica con voluntad en el largo plazo. Como Olmsted pensaba, el tiempo es el escultor del paisaje, pero el tiempo es también ciego. Para que sea posible borrar los límites entre el parque y la naturaleza en el proyecto urbano, el planificador ha de gestionar el tiempo y hacerlo a través de un diseño que, gracias a la perspectiva sistémica, articule los procesos de construcción de la ciudad, de sus infraestructuras y barrios, con el sistema de espacios libres públicos que va tomando forma como garante de unidad y sentido. Antes del discurso sostenible ha estado la preocupación por la ciudad bella y una técnica que supera la justificación higienista y que, como en el Emerald Necklace, construye el paisaje local, facilita la reforma urbana y armoniza el crecimiento expansivo de una ciudad que no puede dejar de ser funcional, y a la vez busca servir a los ciudadanos. Los espacios libres son espacios comunes y pertenecen a la sustancia colectiva que da cohesión a lo urbano ${ }^{33}$. Son su sustrato físico.

En el sistema de parques conviven dos cualidades que lo urbano necesita. Por un lado la escala estructurante de los espacios libres conectados se acerca a lo monumental y contribuye a fortalecer la identidad local. Lo saben Olmsted, al enfrentarse tanto con las 'ciudades sin forma' del Medio Oeste, o Forestier cuando recompone las ciudades de pasado colonial, y lo saben Migge y Blom al enfrentarse con la periferia expansiva de unas ciudades que crecen sin criterio. Todos ellos eran conscientes de la relación profunda que en la ciudad existe entre función y forma. El sistema de parques da forma a lo urbano. Pero a la vez contribuye a la mejora de su metabolismo, cumpliendo una función que trasciende su perfil higienista o su servicio al esparcimiento. La naturaleza que invade lo urbano participa con sus procesos y demuestra un potencial regenerador y creador de salud imprescindible para incrementar la sostenibilidad del complejo territorio urbanizado. Olmsted y Forestier lo intuyen, Migge lo balbucea en sus reflexiones sobre el abastecimiento o el reciclado de residuos en los huertos urbanos, y Blom lo anticipa buscando no una ciudad parque, sino una ciudad en el parque -o en la naturaleza, parafraseando a McHarg. En todo ello, el parque, cada pieza del sistema, necesita un proyecto específico: no es sólo naturaleza. Los cuatro demuestran que el hombre puede ser un agente negentrópico que surge del 'proyectar con la naturaleza'34. No estamos ante un Edén heredado y perdido sino ante un espacio construido, un espacio civilizador. Algo que va más allá de los dibujos que Calvert Vaux hizo para Olmsted, de los de Forestier y Migge, o de los que Erik Glemme hacía junto con Blom, pero que necesita de ellos (fig. 11). RA 
01. La conexión de Olmsted con los paisajistas ingleses (Walks and Talks of an American Farmer in England, OLMSTED, F., Putnam, Nueva York, 1852) coexiste con su interés en diferentes ciencias; ver BEVERIDGE, C. 'Frederick Law Olmsted's 'Theory on Landscape Design, Nineteenth Century', The Journal of the Victorian Society in America, 20, n. 2 (2000), 32-7. Olmsted no fue sólo un gran paisajista, demostró interés específico por las ciudades y talento para su planificación; ver SUTTON, S. B. (ed.), Frederick Law Olmsted, Civilizing American Cities. A Selection of Frederick Law Olmsted's Writings on City Landscape, MIT, Cambridge, Mass., 1971.

02. Utilizamos el concepto de 'sistema' en su acepción común, tal y como lo hacen estos autores, ya que ninguno de ellos desarrolla, específicamente, una visión sistémica en el sentido que le da el urbanismo contemporáneo. Tengamos en cuenta que ésta deriva de su analogía con lo desarrollado por Von Bertalanffy a partir de 1969 con su Teoría General de Sistemas. Sin embargo es evidente que hoy el concepto de sistema de parques, en sentido ecológico amplio, adquiere un significado igualmente más vasto y complejo. La Tesis doctoral Sistema de parques. Origen y evolución de un "principio" estructurador de lo urbano, realizada por Marina Jiménez, bajo la dirección de Juan Luis de las Rivas Sanz, defendida en la Universidad de Valladolid en 2009 , analiza pormenorizadamente la evolución del concepto descubriendo multitud de personajes en la sombra.

03. Algunas de las muchas publicaciones sobre Olmsted que siguen apareciendo desde EEUU: BEVERIDGE, C., Frederick Law Olmsted:Designing the American Landscape. Rizzoli, Nueva York, 1995; RYBZCYNSKI, W. A Clearing in the Distance: Frederick Law Olmsted and North America in the Nineteenth Century, Scribner, Nueva York, 1999; MARTIN, J., Genius of place. The life of Frederick Law Olmsted, Da Capo Press, Cambridge, Mass., 2011.

04. Fechado en 1881 existe un plano con el significativo título: Olmsted's Sketch Map of Buffalo showing the relation of the Park System to the General Plan of the City. La ciudad exhibirá orgullosa su plan en la exposición del centenario de Philadelphia de 1876 bajo el título de The best planned city, as to its streets, public places and grounds, in the United States, if not in the world.

\section{En ZAITZEVSKY, Cynthia, Frederick} Law Olmsted and the Boston Park System, Harvard University Press, Cambridge, Mass., 1982, p. vii. Texto original: "Nothing else compares in importance to us with the Boston work ... I would have you decline any business that would stand in the way of doing the best for Boston all the time".

06. En RACINE, Michel (dir), Créateurs de Jardins et de paysages en France du XIXe siècle au XXIe siécle, Tome II. Actes Sud. École Nationale Supérieure du paysage, 2002, p. 138

07. COHEN, Jean-Louis, “'L'Extension de Paris", en LECLERC, B., (dir., Actas congreso 1990) Jean Claude Nicolas Forestier 1861-1930: Du jardin au paysage urbain. Ed. Picard, Paris, 1994, p. 150.

08. LECLERC, Benedicte, "Forestier et le Service des Promenades", en TEXIER, S., Les parcs et jardins dans l'urbanisme parisien. XIXe-XXe siècles. Action Artistique De La Ville de Paris, 2001, p. 142.

09. IMBERT, Dorothée, "L'Amérique de "Grandes Villes et Systèmes de Parcs", en LECRERC, B. \& TARRAGÓ I CID, S. (dir.) Jean Claude Nicolas Forestier. Grandes villes et systèmes de parcs. France, Maroc, Argentine. Institut Francais d'Architecture, Paris, 1997, p. 366. Indirectamente la Bronx River Parkway también es deudora de un informe elaborado por Olmsted Jr. en 1907 para la ciudad de Nueva York.

10. TARRAGÓ, Salvador, "Entre Le Nôtre y Le Corbusier", en LECLERC, B., op. cit. 1994, p. 261.

11. SEGRE, Roberto, Transformación urbana en Cuba: La Habana, Barcelona, 1974, p. 56.

\section{HANEY, David, "Leberecht Migge's} 'Green Manifesto': Envisioning a revolution of Gardens". En: Landscape Journal, 2007, n. 26, p. 201.

13. De MICHELIS, Marco, "The Red and the Green. Park and City in Weimar Germany", en Lotus, 1981, n. 30, p. 113.

14. Escribe Stübben: "Al inicio de este siglo nos vinieron nuevas ideas y modelos excelentes de los EEUU, donde se desarrollaba enérgicamente la idea de penetrar todo el cuerpo de la ciudad por medio de plantaciones. Los diversos parques fueron reunidos por los denominados parkways... Tales disposiciones constituyen lo que se llama un 'sistema de parques' (Parksystem). Tenemos un ejemplo muy notable de ellos en el sistema de parques de Boston...

Estos paseos internos todavía que yo sepa no han sido introducidos en Francia ni en Italia, pero se puede decir que, nacidos en Inglaterra, han sido aplicados en Alemania con mucha frecuencia en los últimos años"... En "La vegetazione nelle città", en Architettura e Arti decorative, a. V-MCMXXV (1925), pp. 127-145. Este texto va acompañado del plano clásico del Sistema de Parques de Olmsted para Boston. Sin embargo, tanto Stübben en su práctica urbanística, como otros contemporáneos relevantes, como Camilo Sitte, muy diferentes entre sí, no desarrollan la idea de sistema de parques y siguen observando los espacios verdes como elementos aislados de la ciudad, más allá de las relaciones que generan los paseos arbolados.

15. "The older Olmsted was open to these ideas, and the good old families of New England sent Charles Eliot as an understanding representative to Germany. The works of Pückler-Muskau affected Eliot like an epiphany; he carried the precious seed that would have dried up in Germany back to his homeland and brought it to an unexpected flowering in the park systems of Boston. From there, these ideas should return to Germany". HEGEMANN, 1912, en HANEY, D., "Bringing the Americanized Pückler back to Germany: Charles Eliot and the German Park Reform Movement", en GHI Bulletin Suplement 4, 2007, p. 91.

16. "Migge liked the concept of interconnected park systems, giving them a variety of social functions and spatial expressions. Migge adopted the American way of taking in meadows and woodlands as part of the cultural landscape of the park, and spaces that could be used for public gatherings". WAYMARK, J., "When Modern Was Green: Life and Work of Landscape Architect Leberecht Migge (review)", Landscape Journal, 2011, n. 30, p. 153. 
17. De MICHELIS, M., op. cit., p. 114.

18. MOHR, C. \& MÜLLER, M., Funktionalität und Moderne. Das Neue Frankfurt und seine Bauten 1925-1933. Ed. Fricke, Frankfurt/Main, 1984, p. 26.

19. DANIELSSON, T., 1965. Postilla. Citado en la exposición sobre Blom en el Centro Sueco para la Arquitectura y el Diseño (hoy ArkDes).

20. ANDERSON, Thorbjorn, "To Erase the Garden: Modernity in the Swedish Garden and Landscape", en: TREIB, M. The Architecture of Landscape 19401960, University of Pennsylvania Press, Philadelphia, 2002, p. 22.

21. Cuando en 2009 la ciudad convoca un concurso para un puesto renovado de jardinero municipal, una publicación de arquitectura difunde la convocatoria con el titular "Stockholm's parks are looking for new champion", www.arkitekt.se/ s494789 (consulta 27-03-2012). El título de dynamisk stadsträdgårdsmästare lo vemos en un texto sueco reciente sobre su figura: ÅSBRINK, B. Holger Blom. Dynamisk trädgårdsmästare i Stockholm, Carlsson Bokförlag, Estocolmo, 2012.

22. Un proceso que no es simple. El sueco L. Bolin escribe en 1947: 'We have now endeavored to let nature slip into the city again, after times when we tried to destroy most of it.' Citado por ANDERSON, Thorbjorn, "Erik Glemme and the Stockholm Park System". En: TREIB, M., Modern Landscape Architecture: a Critical Review. University of Pennsylvania Press, Filadelfia, 1993, p. 118.

23. Blom sigue siendo reconocido como el gran 'gestor' de la estructura verde de Estocolmo (nombrada Primera Capital Verde Europea en 2010), capaz de fortalecer la singular relación de la ciudad con su entorno natural.

24. Blom utiliza para persuadir a los políticos una cartulina con su programa condensado: The park relieves (or opens up) the city; the park provides space for outdoor recreation; the park offers space for public gatherings; the park preserves nature and culture... abordando escalas y temas diversos, de actualidad indiscutible: the urban planning aspect; the sanitary and general health aspect; the social aspect; the ecological aspect. Cartulina referida en ANDERSSON, T., “To Erase...”, op. cit., p. 22.

25. The park relieves ["opens up"] the city: The park must be an active component of urban development, forming networks through the city, and not just an isolated green oasis. Folleto Exposición "Eating-out", junio-septiembre 2008. Arkitekturmuseet de Estocolmo.

26. ANDERSSON, T. “Erik Glemme...”, op. cit.; SUNDSTROM, E., "The Restoration of Norr Mälarstrand: A linear park of the Stockholm School", en Garden History, 2004, 32, n. 2.

\section{JELLICOE, Geofrey, The landscape} of man: shaping the environment from prehistory to the present day, Thames and Hudson, Londres, 1987, p. 301.

28. En la figura reconocemos el Tantolunden en Soderlman, cuyo origen es de fines del $\mathrm{XIX}$; los terrenos de Eriksdalslunden al sur, con comunidades jardineras activas ya desde 1900s; más al sur y casi virgen, el Skogskyrkogarden, acondicionado por Asplund y Lewerentz desde 1915; los Djurgarden Sur a E-NE, con el Skansen, primer museo al aire libre del mundo, $y$ Djurgarden Norte, enlazados a través de la zona de Gardet, con edificaciones en bloque abierto construidas en los años 30 , continuando hacia el Hagaparken; al Este penetra la red verde en la ciudad central desde las ciudades satélite HässelbyVallingby y Bromma, llegando al sistema encadenado del Kungshomen, del Fredhålls parken al Rålambmovsparken.

29. Reconocido no sólo por el experto sueco T. Andersson, sino por autores diversos, especialistas en cuestiones del verde urbano, como G. Jellicoe, F. Migliorini, F. Panzini, E. Battle, etc.

30. En 1968 la Ciudad de Estocolmo (compuesta a su vez por 19 distritos en desarrollo) se integraba en el Condado, hasta entonces formado por las 25 municipalidades del entorno, con planeamiento unificado en lo que es la región urbana de Estocolmo.
31. PANZINI, Francesco, Per i Piaceri del Popolo. L'evoluzione del giardino pubblico in Europa dalle origini al XX secolo. Zanichelli, Bolonia, 1993, p. 315.

32. Cita de NELSON, A., Investigación sobre Sistemas de espacios libres desarrollada por la Universidad del Estado de Washington, EEUU. Estudio de caso: Estocolmo. 2006, p. 2. Disponible en: http://depts.washington.edu/open2100/ Resources/1_OpenSpaceSystems/Open_ Space_Systems/Stockholm_Case_Study. pdf. Último acceso 10.02.2018. En el diseño de algunos espacios libres de las ciudades dormitorio, Vällingby entre otras, hubo una interesante innovación lingüística con Glemme como principal responsable, que Markelius y Blom apoyan cuando la opinión popular parece contraria, como en la urbanización ribereña de Hässelby a finales de los 50s. Donde algunos contraponen la continuidad sueca del paisaje frente al parque aislado y circunscrito inglés (MIGLIORINI, F. Verde urbano: parchi, giardini, paesaggio urbano, lo aperto nella costruzione della città moderna. Franco Angeli, Milán, 1989, p.196), un "paisaje borrado" (ANDERSSON, T. "To Erase..." 2002), otros ven paralelismo entre el espacio verde sueco y el village green o common anglosajón, apoyándose en su vocación de uso comunitario, aunque cuestionando la voluntad de crear un gran sistema de verde unificado (PANZINI, ibid., p. 316).

33. Recordemos las cuatro categorías básicas que ofrece G. Cranz para el parque americano: Pleasure Ground de Olmsted (1850-1900); Reform Park (1900-1930); Recreational Facility -Equipment-(1930-1965); Open Space System (1965-1990). Ver: CRANZ, Galen, The Politics of Park Design: A History of Urban Parks in American, MIT Press, Cambridge, Mass., 1982. A ellas añade desde los 90s el Sustainable Park (CRANZ, G., "Defining the Sustainable Park: A Fith Model for Urban Parks". En: Landscape Journal, 2004, n. 23:2-04, pp. 102-120).

34. McHARHG, lan, Design with Nature, Primera edición, 1969 (American Museum of Natural History, Natural History Press), edición en castellano 2000, Gustavo Gili, Barcelona. 


\section{Referencias bibliográficas}

\begin{abstract}
- ANDERSON, T., "To Erase the Garden: Modernity in the Swedish Garden and Landscape". En TREIB, M., The Architecture of Landscape 1940-1960, University of Pennsylvania Press, Philadelphia, 2002.
\end{abstract}

- ANDERSON, T., "Erik Glemme and the Stockholm Park System", en TREIB, M., Modern Landscape Architecture: a Critical Review, University of Pennsylvania Press, Filadelfia, 1993.

-BATTLE, E., El jardín de la metrópoli. Del paisaje romántico al espacio libre para una ciudad sostenible, Gustavo Gili, Barcelona 2011.

- BEVERIDGE, C.\& ROCHELEAU, P., Frederick Law Olmsted:Designing the American Landscape, Rizzoli, Nueva York, 1995.

- CRANZ, G., The Politics of Park Design: A History of Urban Parks in American, MIT Press, Cambridge, Mass., 1982.

- DE MICHELIS, M., “The Red and the Green. Park and City in Weimar Germany", en Lotus, 1981, n. 30.

- FORESTIER, J. C. N., Grandes villes et systèmes de parcs, Hachette, París, 1908.

- FORESTIER, J. C. N., Jardines: Cuaderno de Dibujos y Planos, Stylos, Barcelona, 1985.

-JELLICOE, G., The landscape of man: shaping the environment from prehistory to the present day, Thames and Hudson, Londres, 1987.

- JIMÉNEZ, M. Sistema de parques. Origen y evolución de un "principio" estructurador de lo urbano, Tesis doctoral desarrollada bajo la dirección de Juan Luis de las RIVAS SANZ, defendida en la Universidad de Valladolid, 2009.

- HANEY, D., "Bringing the Americanized Pückler back to Germany: Charles Eliot and the German Park Reform Movement", en GHI Bulletin Suplement 4, 2007.

- HANEY, D., When Modern was Green. Life and work of landscape architect Leberecht Migge, Routledge, New York, 2010.

- LECLERC, B., (dir., Actas congreso 1990), Jean Claude Nicolas Forestier 1861-1930: Du jardin au paysage urbain, Ed. Picard, Paris, 1994.
- LECRERC, B. \& TARRAGÓ I CID, S., (dir.), Jean Claude Nicolas Forestier. Grandes villes et systèmes de parcs. France, Maroc, Argentine, Institut Francais d'Architecture, Paris, 1997.

- MIGLIORINI, F., Verde urbano: parchi, giardini, paesaggio urbano, lo aperto nella costruzione della città moderna, Franco Angeli, Milán, 1989

- MOHR, C. \& MÜLLER, M., Funktionalität und Moderne. Das Neue Frankfurt und seine Bauten 1925-1933, Ed. Fricke, Frankfurt/ Main, 1984.

- OLMSTED, F. O., Walks and Talks of an American Farmer in England, Putnam, Nueva York, 1852.

- PANZINI, F., Per i Piaceri del Popolo. L'evoluzione del giardino pubblico in Europa dalle origini al $X X$ secolo, Zanichelli, Bolonia, 1993.

- RACINE, M., (dir), Créateurs de Jardins et de paysages en France du XIXe siècle au XXIe siécle, Tome II, Actes Sud, École Nationale Supérieure du paysage, 2002.

- RYBZCYNSKI, W., A Clearing in the Distance: Frederick Law Olmsted and North America in the Nineteenth Century, Scribner, Nueva York, 1999.

-STUBBEN, J., "La vegetazione nelle città", en Architettura e Arti decorative, a. V-MCMXXV, 1925.

- SUTTON, S. B. (ed.), Frederick Law Olmsted, Civilizing American Cities. A Selection of Frederick Law Olmsted's Writings on City Landscape, MIT, Cambridge, Mass., 1971.

- TEXIER, S., Les parcs et jardins dans l'urbanisme parisien. XIXe - XXe siècles. Action Artistique De La Ville de Paris, 2001.

- ZAITZEVSKY, C., Frederick Law Olmsted and the Boston Park System, Harvard University Press, Cambridge, Mass., 1982.
RA. Revista de Arquitectura Núm. 20 - 2018 P. 86-103 